\title{
Retracted: Performance Analysis of High-Speed Deep/Shallow Recessed Hybrid Bearing
}

\section{Mathematical Problems in Engineering}

Received 10 November 2014; Accepted 10 November 2014; Published 11 November 2014

Copyright (C) 2014 Mathematical Problems in Engineering. This is an open access article distributed under the Creative Commons Attribution License, which permits unrestricted use, distribution, and reproduction in any medium, provided the original work is properly cited.

This article [1] has been retracted as it was submitted for publication without the knowledge and approval of the coauthor Shuyun Jiang.

\section{References}

[1] L. Wang and S. Jiang, "Performance analysis of high-speed deep/shallow recessed hybrid bearing," Mathematical Problems in Engineering, vol. 2013, Article ID 918767, 9 pages, 2013. 


\title{
Performance Analysis of High-Speed Deep/Shallow
} Recessed Hybrid Bearing

\author{
Lei Wang and Shuyun Jiang \\ School of Mechanical Engineering, Southeast University, Nanjing 211189, China
}

Correspondence should be addressed to Shuyun Jiang; jiangshyseu@gmail.com

Received 10 June 2013; Accepted 5 November 2013

Academic Editor: Tirivanhu Chinyoka

Copyright (C) 2013 L. Wang and S. Jiang. This is an open access article distributed under the Creative Commons Attribution License, which permits unrestricted use, distribution, and reproduction in any medium, provided the original work is properly cited.

The present paper proposes a theoretical analysis of the performance of deep/shallow recessed hybrid bearing. It is intended that, on the basis of the numerical results drawn from this study, appropriate shallow recess depth and width can be determined for use in the bearing design process. By adopting bulk flow theory, the turbulent Reynolds equation and energy equation are modified and solved numerically including concentrated inertia effects at the recess edge with different depth and width of shallow recess. The results indicate that the load capacity, drag torque increases as the depth of shallow recess is shallower and the width ratio (half angle of deep recess versus half angle of shallow recess) is smaller. In contrast, the flow rate decreases as the depth of shallow recess is shallower and the width ratio is smaller. Nevertheless, the appropriate design of the depth and width of shallow recess might well induce the performance of high-speed deep/shallow recessed hybrid bearing.

\section{Introduction}

The hybrid journal bearings provide superior performance characteristics such as minimum friction, large fluid film stiffness, good damping characteristics, and smooth relative motion. Due to the characteristics of excellent stiffness and damping, good rotational accuracy, low friction, and long life, they can be an attractive alternative to rolling bearings in high-speed machine tool spindle $[1,2]$. The hybrid bearings have many types, the deep/shallow recess bearings are a common form of hybrid bearings, and the hydrodynamic effects of these bearings are greatly improved and have the merits of larger load capacity, higher stiffness, and superior stability than many other types of hybrid bearings. Despite all that, the main drawback of these bearings is large heat generation in high-speed condition; therefore, the low-viscosity fluid is adopted in the high-speed deep/shallow recess hybrid bearing to satisfy the demands of high-speed machine tool spindle since the low viscosity can significantly reduce the friction loss and heat generation.

During the last few decades, the theoretical analysis of the hybrid bearings with deep/shallow recesses has been carried out and reported in the literature. Among the first studies were the principles of these bearings [3]. Also the static and dynamic characteristics of deep/shallow recessed hybrid bearings were studied, respectively, with different structure of bearing [4-6], different restrictors [7], various recess shapes $[8,9]$, and considering different flow regime and operational condition [10]. The depth and width of shallow recess were a key design parameter for hybrid bearings with deep/shallow recess. The following review details some important investigation carried out for the influence of shallow recess depth and width on the hybrid bearings.

Chen et al. [11, 12] studied the influence of the shallow recess depth on the performance of hybrid bearing with orifice compensated and capillary compensated. Compared to the conventional deep recess bearing, they put forward the design criterion of shallow recess depth about the hybrid bearing. Helene et al. [13] presented the theoretical analysis of the pressure pattern in a two-dimensional recess of a hybrid journal bearing. They introduced the ratio of the recess depth versus the film thickness. Six values of this ratio are considered, ranging from 4 (shallow recess) to 152 (deep recess), and presented in a systematic manner giving a clear insight of the flow effects intervening in the recess and of their mutual interaction with laminar and turbulent conditions. 
The above references have been instrumental to the present development. Due to the high surface speed, the highspeed hybrid bearing with deep/shallow recesses using the low-viscosity fluid is always operated in the turbulent flow regime; meanwhile the inertia effects are also pronounced, especially the concentrated inertia effects at the edge of deep recess. To the best knowledge of authors, a thorough scan of the available literature reveals that there does not exist any comprehensive study related to the performance of the highspeed deep/shallow recessed hybrid bearing with different depth and width of shallow recess considering the turbulent flow regime and inertia effects in thermohydrodynamic lubrication analysis.

In the present study, an analysis is conducted and solutions are provided for the effects of the depth and width of shallow recess on the performance of the high-speed deep/shallow recessed hybrid bearing. By adopting bulk flow theory, the turbulent Reynolds equation and energy equation are modified and solved numerically including concentrated inertia effects at the deep recess edge with different eccentricity ratios.

\section{Theoretical Analysis}

2.1. The Geometry of High-Speed Hybrid Bearing with Deep/ Shallow Recesses. Figure 1 shows the geometry of high-speed hybrid bearing with four deep/shallow recesses and feed orifices. The deep/shallow recess is comprised of two parts, the shallow recess and deep recess; the pressurized fluid is supplied into the deep recess through orifice, a flow from deep recess into the shallow recess and film land.

2.2. Turbulent Reynolds Equation. The generalized nondimensional Reynolds equation for the turbulent flow regime can be written as

$\frac{\partial}{\partial \theta}\left(G_{x} \frac{\bar{H}^{3}}{\bar{\mu}} \frac{\partial \bar{p}}{\partial \theta}\right)+\left(\frac{D}{L}\right)^{2} \frac{\partial}{\partial \bar{z}}\left(G_{z} \frac{\bar{H}^{3}}{\bar{\mu}} \frac{\partial \bar{p}}{\partial \bar{z}}\right)=\Lambda \frac{\partial \bar{H}}{\partial \theta}+\sigma \frac{\partial \bar{H}}{\partial \tau}$

where nondimensional parameters are defined by

$$
\begin{gathered}
\theta=\frac{x}{R}, \quad \bar{z}=\frac{z}{L / 2}, \quad \bar{H}=\frac{h}{c}, \quad \bar{p}=\frac{p}{P_{s}}, \\
\bar{\mu}=\frac{\mu}{\mu_{0}}, \quad \Lambda=\omega_{p} \cdot t, \quad \Lambda=\frac{\mu_{0} \cdot \omega \cdot R^{2}}{2 p_{s} c^{2}}, \\
\sigma=\frac{\mu_{0} \cdot \omega_{p} \cdot R^{2}}{p_{s} \cdot c^{2}},
\end{gathered}
$$

where the turbulent coefficients $G_{x}$ and $G_{z}$ depend on the fluid velocity field and are smaller than $1 / 12$ which is the value they take in the case of laminar flow.

2.3. The Bulk Flow Model for Turbulent Lubrication. Returning to the Navier-Stokes equations for a turbulent thin film

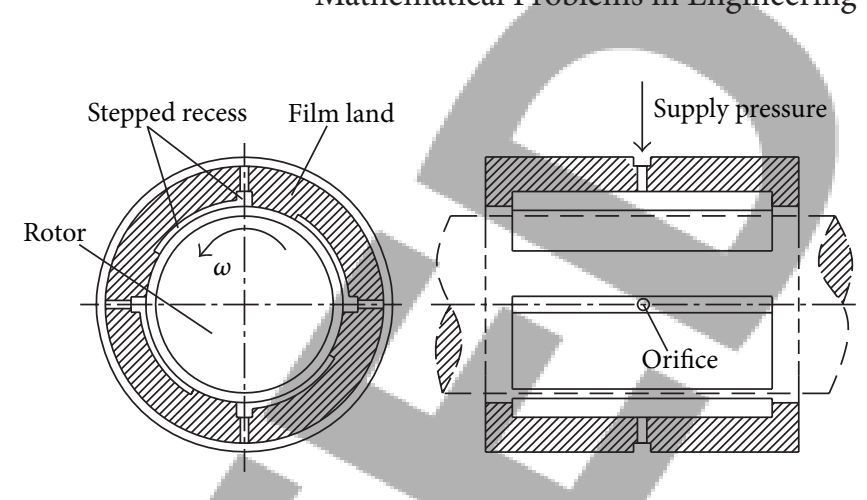

FIGURE 1: Geometry of the high-speed hybrid bearing with deep/ shallow recesses.

and disregarding the inertia terms, after integration, the bulkflow speed components can be expressed in the following form [14]:

$$
V_{x}=-G_{x} \frac{h^{2}}{\mu} \frac{\partial p}{\partial x}+\frac{U}{2}, \quad V_{z}=-G_{z} \frac{h^{2}}{\mu} \frac{\partial p}{\partial z} .
$$

Here $V_{x}$ and $V_{z}$ are the mean values across the film of the stochastic averages of the fluid velocity components. Following the bulk flow theory of Hirs, the pressure gradient depends on the bulk flow velocity [15]:

$$
\begin{gathered}
-h \frac{\partial \bar{p}}{\partial x}=\frac{\mu}{h}\left\{\frac{1}{2}\left(k_{J}+k_{B}\right) V_{x}+k_{J} \frac{U}{2}\right\}, \\
-h \frac{\partial \bar{p}}{\partial z}=\frac{\mu}{h}\left\{\frac{1}{2}\left(k_{J}+k_{B}\right) V_{z}\right\},
\end{gathered}
$$

where the turbulent shear parameters at shaft and bearing $\left(k_{J}\right.$, $k_{B}$ ) are defined in terms of the flow Reynolds numbers relative to the rotating shaft and stationary bearing surfaces:

$$
k_{J}=0.066 \operatorname{Re}_{J}^{0.75}, \quad k_{B}=0.066 \operatorname{Re}_{B}^{0.75}
$$

The flow Reynolds numbers relative to the rotating shaft and stationary bearing surfaces are

$$
\begin{aligned}
\operatorname{Re}_{B} & =\frac{\rho h}{\mu}\left[V_{x}^{2}+V_{z}^{2}\right]^{1 / 2}, \\
\operatorname{Re}_{J} & =\frac{\rho h}{\mu}\left[\left(V_{x}-U\right)^{2}+V_{z}^{2}\right]^{1 / 2} .
\end{aligned}
$$

Comparing (3), (4) the turbulent coefficients are obtained as

$$
\begin{gathered}
G_{x}=\min \left[\frac{1}{12} ; \frac{2 V_{x}-U}{\left(k_{J}+k_{B}\right) V_{x}-k_{J} U}\right], \\
G_{z}=\min \left[\frac{1}{12} ; \frac{2}{\left(k_{J}+k_{B}\right)}\right] .
\end{gathered}
$$

2.4. The Concentrated Inertia Effects at the Edge of Deep Recess. The local acceleration of fluid film from a deep recess into shallow recess and film land causes a sudden pressure drop in the high-speed condition $[16,17]$; the pressure at the entrance 
to shallow recess and film land is modeled from Bernoulli's equation as

$$
p_{e}=p_{r}-\frac{\rho V_{x, z}^{2}}{2}(1+\xi) \quad\left(V_{x, z} \cdot n>0\right) .
$$

Note that the entrance loss coefficient $\xi$ is expressed as the empirical (edge) entrance loss coefficients.

2.5. Energy Equation. The energy equation under adiabatic conditions in turbulent flow regime is obtained as follows:

$$
\rho\left[\frac{\partial\left(c_{v} T h V_{x}\right)}{\partial x}+\frac{\partial\left(c_{v} T h V_{z}\right)}{\partial z}\right]=\left.\tau_{x y}\right|_{0} U-\left.\tau_{x y}\right|_{0} ^{h} V_{x}-\left.\tau_{z y}\right|_{0} ^{h} V_{z},
$$

where

$$
\begin{gathered}
\left.\tau_{x y}\right|_{0}=\frac{h}{2} \frac{\partial p}{\partial x}+\frac{\mu}{4 h}\left[k_{b} V_{x}-\left(V_{x}-U\right) k_{J}\right], \\
\left.\tau_{x y}\right|_{0} ^{h}=-\frac{\mu}{h}\left(k_{x} V_{x}-k_{J} \frac{U}{2}\right), \\
\left.\tau_{z y}\right|_{0} ^{h}=-\frac{\mu}{h}\left(k_{z} V_{z}\right) .
\end{gathered}
$$

The energy equation becomes in nondimensional form:

$$
\begin{aligned}
\rho[ & \left.\frac{\partial\left(c_{v} \bar{T} \bar{H} V_{x}\right)}{\partial \theta}+\left(\frac{D}{L}\right) \frac{\partial\left(c_{v} \overline{T H} V_{z}\right)}{\partial(Z)}\right] \\
= & {\left[\frac{p_{s}}{2 T_{s}} \frac{\bar{H} \bar{p}}{\partial \theta}\right] U+\left[\frac{\mu_{0} R}{c^{2} T_{s}} \frac{\bar{\mu}}{4 \bar{H}}\left[k_{b} V_{x}-\left(V_{x}-U\right) k_{J}\right]\right] U } \\
& +\left[\frac{\mu_{0} R}{c^{2} T_{s}} \frac{\bar{\mu}}{\bar{H}}\left(k_{x} V_{x}-k_{J} \frac{U}{2}\right)\right] V_{x}+\frac{\mu_{0} R}{c^{2} T_{s}} \frac{\bar{\mu}}{\bar{H}}\left(k_{z} V_{z}\right) V_{z},
\end{aligned}
$$

where $\bar{T}=T / T_{s}$.

The fluid viscosity is considered to vary with temperature according to the following formulae:

$$
\mu=b e^{-a\left(t-t_{0}\right)} \text {. }
$$

2.6. Drag Torque. The turbulent wall shear stress at the journal surface based on bulk flow theory is given by [18]

$$
\left.\tau_{x y}\right|_{0}=\frac{h}{2} \frac{\partial p}{\partial x}+\frac{\mu}{4 h}\left(V_{x} k_{b}-\left(V_{x}-\omega R\right) \cdot k_{J}\right) .
$$

The drag torque is given by integration of the wall shear stress at the journal surface:

$$
T_{f}=\int_{-L / 2}^{-L / 2} \int_{0}^{2 \pi R} \tau_{y x} R d x d z
$$

2.7. Mass Conservation at a Deep Recess. The continuity equation at the deep recess is defined by the global balance between the flow through the orifice restrictor $\left(Q_{\text {in }}\right)$, the

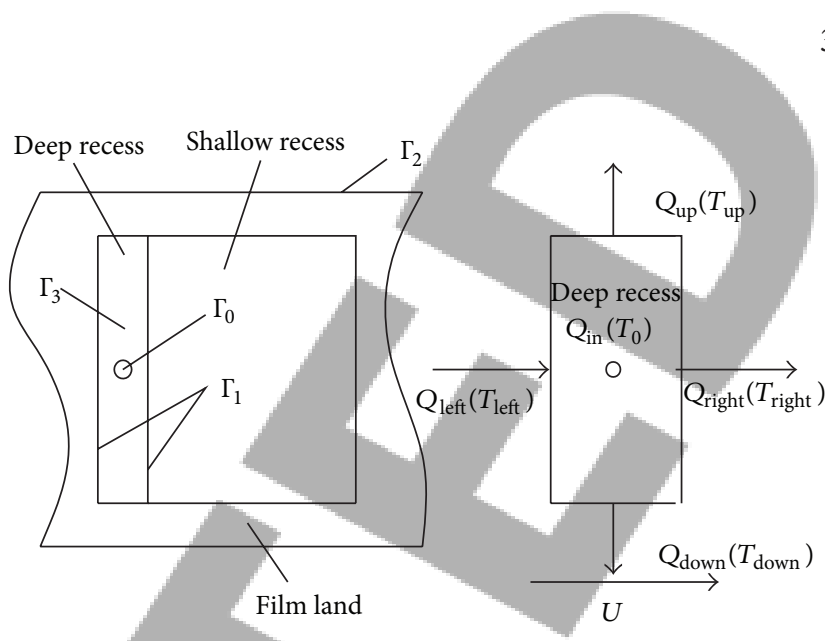

FIGURE 2: Boundary conditions and conceptual description of global flow rate and energy balance at a deep recess.

recess outflow into the shallow recess and film land $\left(Q_{\text {out }}\right)$, and the time rate of mass changing due to squeeze effect $\left(Q_{j}\right)$. The recess flow continuity equation is expressed as

$$
Q_{\text {in }}=Q_{\text {out }}+Q_{j}
$$

where the flow through the orifice restrictor is

$$
Q_{\text {in }}=A_{0} C_{d} \sqrt{\frac{2\left(p_{s}-p_{r}\right)}{\rho}} .
$$

The recess outflow into the shallow recess and film land is comprised of two parts, the flow across axial and circumferential boundaries of the deep recess:

$$
Q_{\text {out }}=Q_{\text {outa }}+Q_{\text {outc }} \text {. }
$$

The time rate of mass changing due to squeeze effect is determined as follows:

$$
Q_{j}=A_{r} \frac{\partial h}{\partial t}
$$

2.8. Global Energy Balance Equation at a Deep Recess. The energy leaving the boundary of the deep recess must be equal to the energy flowing into the deep recess (Figure 2); that is,

$$
E_{\text {in }}=E_{\text {out }} .
$$

(1) The energy flowing into the deep recess is comprised of two parts, the carry-over of hot fluid from upstream to downstream of the deep recess and the fresh fluid from the supply source into the deep recess volume [19]:

$$
E_{\text {in }}=q_{\text {in }} T_{s}+q_{\text {left }} T_{\text {left }}
$$

(2) The energy leaving the boundary of the deep recess is expressed as

$$
E_{\text {out }}=q_{\text {right }} T_{\text {right }}+q_{\text {up }} T_{\text {up }}+q_{\text {down }} T_{\text {down }} .
$$


TABLE 1: The parameters of high-speed deep/shallow recessed hybrid bearing.

\begin{tabular}{lcc}
\hline Bearing diameter $(\mathrm{mm})$ & Bearing length $(\mathrm{mm})$ & Orifice diameter $(\mathrm{mm})$ \\
\hline$D=60$ & $L=60$ & $d_{c}=1$ \\
\hline Rotor speed $(\mathrm{rpm})$ & Depth of deep recess $(\mathrm{mm})$ & Inlet temperature $\left(^{\circ}\right)$ \\
\hline$\omega=30000$ & $h_{p}=0.5$ & $T_{0}=20$ \\
\hline Half angle of recess $\left(^{\circ}\right)$ & Depth of shallow recess $(\mathrm{mm})$ & Width ratio of shallow recess \\
\hline$\theta=0-30$ & $h_{r}=0.01-0.05$ & $k=0.25-4$ \\
\hline Radial clearance $(\mu \mathrm{m})$ & Viscosity $(\mathrm{pa} \cdot \mathrm{s})$ & Supply pressure $(\mathrm{Mpa})$ \\
\hline$c=20$ & $\mu_{0}=0.001$ & $P_{s}=3$ \\
\hline$k$ is the width ratio, $k=\theta_{d}: \theta_{s}, \theta_{d}:$ half angle of deep recess, and $\theta_{s}:$ half angle of shallow recess. & \\
When $k=0$ or $k=\infty$, the deep/shallow recess is changed to shallow or deep recess. &
\end{tabular}

2.9. Boundary Conditions. The boundary conditions for the pressure and temperature fields on the high-speed deep/ shallow recessed hybrid bearing which are shown in Figure 2 are expressed as follows.

\subsubsection{Pressure Boundary Conditions}

(1) The pressure at the ends of the bearing is taken to be equal to the ambient pressure. Thus,

$$
\left.p\right|_{\Gamma=\Gamma_{2}}=p_{a}
$$

(2) The depth of deep recess is much greater than the film thickness; it is assumed that the pressure in each deep recess is uniform and equal to

$$
\left.p\right|_{\Gamma=\Gamma_{3}}=p_{r}
$$

(3) Fluid inertia at the edges of deep recess is treated through a Bernoulli-type relationship.

(4) The supply pressure is equal to

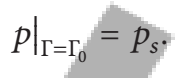

(5) On the $360^{\circ}$ extended film land, the pressure field is continuous and single-valued in the circumferential direction:

$$
p(\theta, z)=P(\theta+2 \pi, z)
$$

\subsubsection{Temperature Boundary Conditions}

(1) The temperature of the deep recess and edges is obtained as described above; that is,

$$
\left.T\right|_{\Gamma=\Gamma_{3}}=T_{r},\left.\quad T\right|_{\Gamma=\Gamma_{1}}=T_{r} .
$$

(2) The supply temperature is equal to

$$
\left.T\right|_{\Gamma=\Gamma_{0}}=T_{s} \text {. }
$$

(3) On the $360^{\circ}$ extended film land, temperature field is continuous and single-valued in the circumferential direction:

$$
T(\theta, z)=T(\theta+2 \pi, z) .
$$

\section{Result and Discussion}

The parameters of high-speed deep/shallow recessed hybrid bearing are chosen from Table 1.

3.1. Fluid-Film Pressure Distribution. The distribution of fluid-film pressure along circumferential direction at axial midplane is shown in Figure 3. It is observed from the figure that the hydrodynamic effects of high-speed hybrid bearing with deep/shallow recesses are significant and the peak pressure is higher as the width ratio decreases; the shallow recessed bearing $(k=0)$ has the maximum peak pressure; however, the pressure distribution changes slowly and has no peak pressure along circumferential direction for the deep recessed bearing $(k=\infty)$ since the hydrodynamic effects are the lowest; meanwhile the pressure has a sharp decrease at the downstream edge of deep recess due to the concentrated inertia effects. Furthermore, from Figure 7(b), it can be seen that the hydrodynamic effects of high-speed deep/shallow recessed hybrid bearing are more pronounced as the depth of shallow recess is shallower. The peak pressure is located at the downstream of shallow recess.

3.2. Fluid-Film Temperature Distribution. The profile of fluidfilm temperature along circumferential direction at axial midplane is depicted in Figure 4. It is noticed that the bearing temperature rise increases as the depth of shallow recess is shallower and the width ratio is smaller due to the increase of drag torque and the reduction of flow rate caused by hydrodynamic effects. The temperature is found higher at almost all the points along circumferential directions for the shallow recessed bearing and has the maximum peak value (almost $60^{\circ}$ ); however, due to the large flow rate the temperature rise of deep recessed bearing changes not obviously and the value of temperature is not beyond $30^{\circ}$ which showed the advantages of hybrid bearing using the low viscosity fluid under the high-speed condition. Further, it is also observed that the temperature rise of high-speed hybrid bearing with deep/shallow recesses is high (almost $60^{\circ}$ ) with the shallower depth of shallow recess $\left(h_{r}=10 \mu \mathrm{m}\right)$ and the smaller width ratio $(k=1: 4)$ due to the combination of hydrodynamic and turbulent effects. 


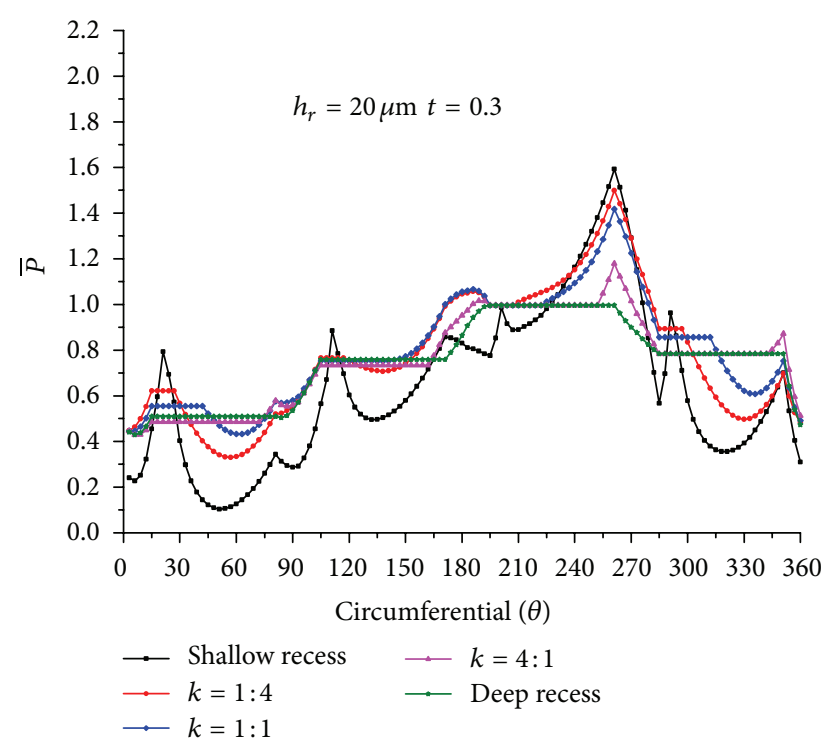

(a)

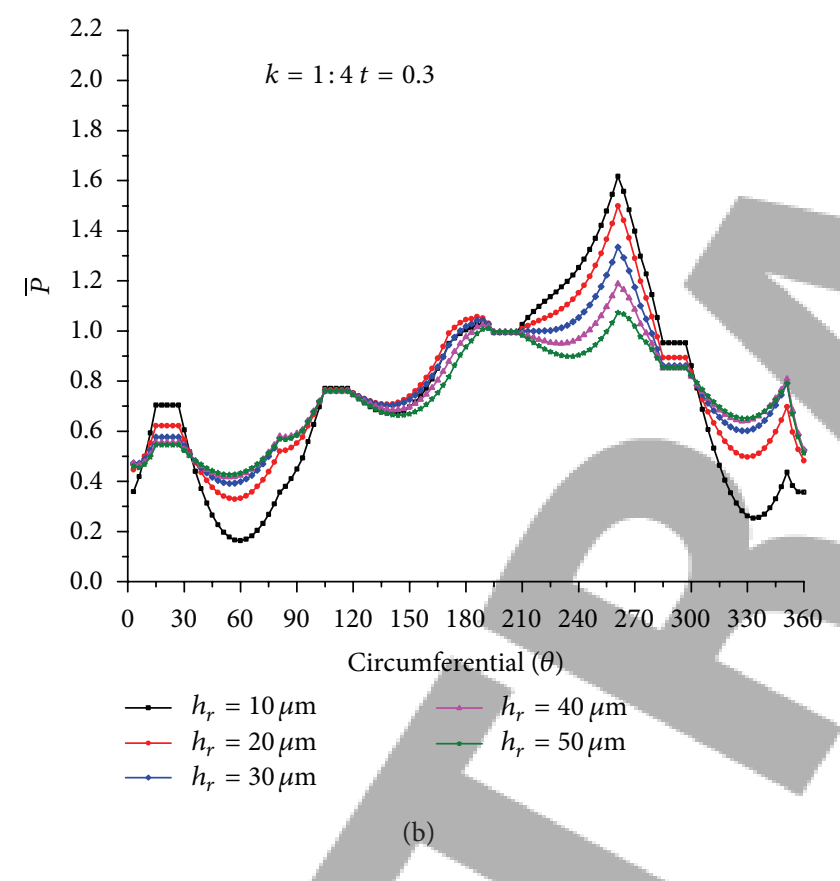

Figure 3: Pressure distribution for the high-speed deep/shallow recessed hybrid bearing.

3.3. Static Load Capacity. Figure 5 shows the static load capacity of high-speed deep/shallow recessed hybrid bearing versus the eccentricity ratio. Note that the static load capacity exhibits a remarkable enhancement as the eccentricity ratio is larger owing to the increase of hydrodynamic effects. The static load capacity increases as the depth of shallow recess is shallower and the width ratio is smaller; meanwhile, the static load capacity of deep/shallow recessed bearing is larger than the deep recessed bearing and almost twice as large as deep recessed bearing for smaller width ratio $(k=1: 4)$ at large eccentricity ratio $(\varepsilon>0.7)$. It can be explained that the predominance of hydrodynamic effects gets over hydrostatic

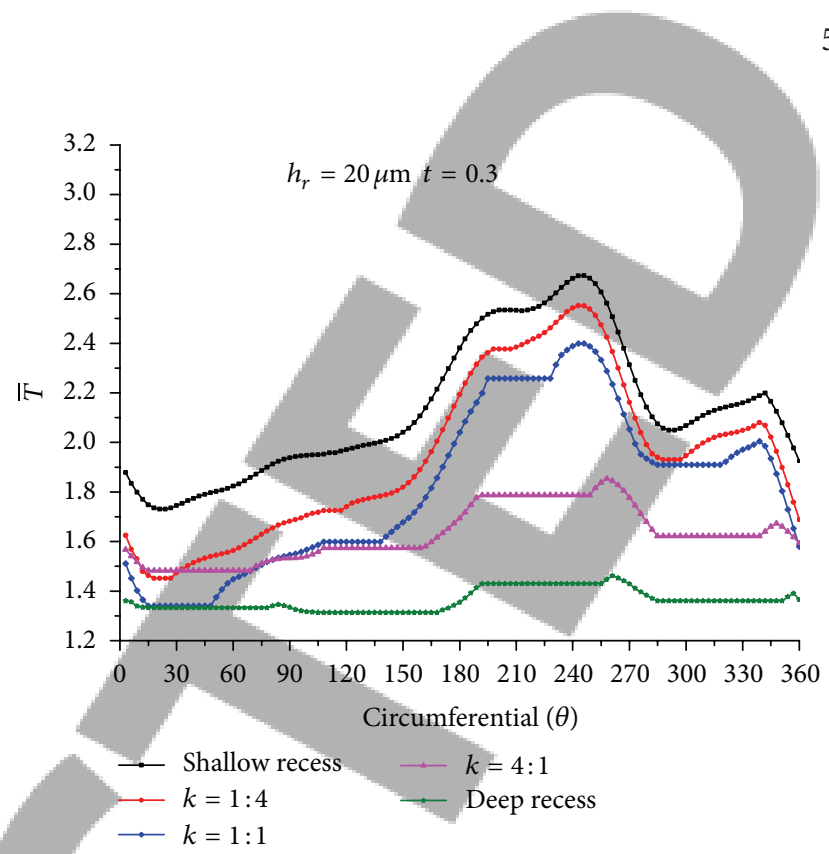

(a)

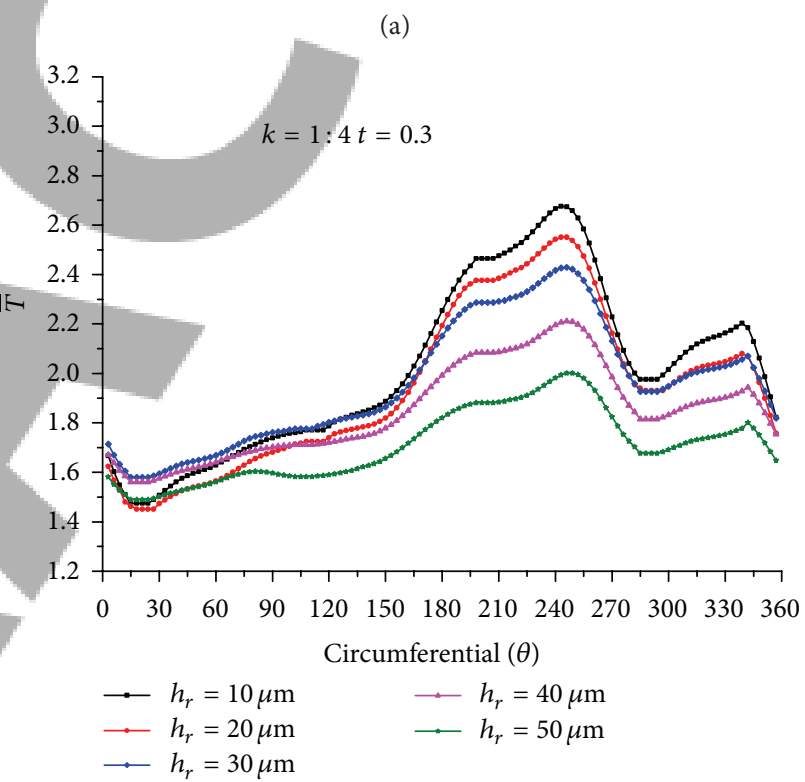

(b)

FIGURE 4: Temperature distribution for the high-speed deep/shallow recessed hybrid bearing.

effects with the increase of eccentricity ratio. Moreover, when the width ratio becomes smaller $(k=1: 4)$ or larger $(k=4: 1)$, the static load capacity of deep/shallow recessed bearing is close to the shallow recessed bearing or the deep recessed bearing, respectively.

3.4. Attitude Angle. Figure 6 shows the attitude angle of high-speed hybrid bearing with deep/shallow recesses against the eccentricity ratio. It can be seen that the attitude angle decreases with the eccentricity ratio except for the deep recessed bearing. The attitude angle is larger with the shallower depth of shallow recess and the smaller width ratio especially for small eccentricity ratio due to the increase of hydrodynamic effects. Further, the attitude angle of shallow 


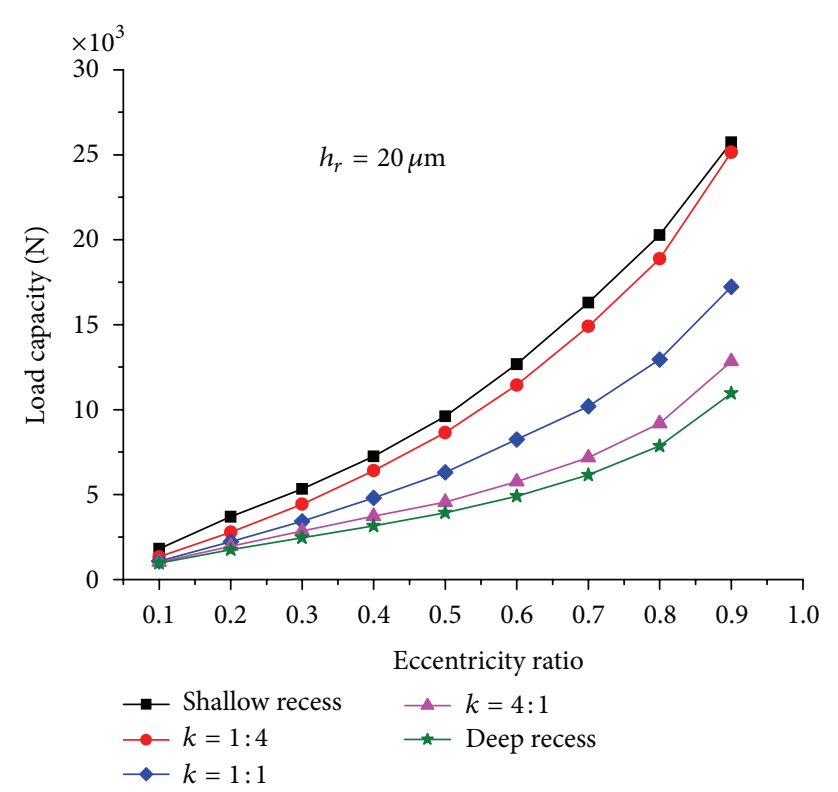

(a)

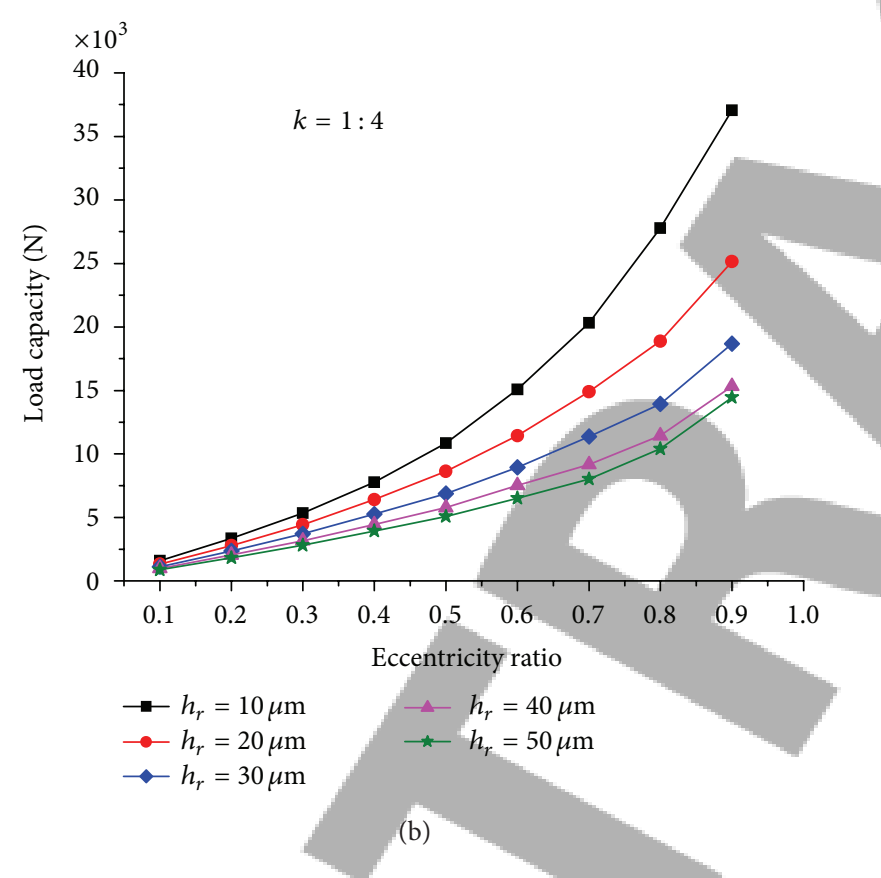

FIGURE 5: Static load capacity versus eccentricity ratio.

recessed bearing is the largest $\left(80^{\circ}\right)$ at lower eccentricity ratio $(\varepsilon<0.3)$ and decreases rapidly with the increase of eccentricity ratio; however, the attitude angle of deep recessed bearing is almost constant at lower eccentricity ratio $(\varepsilon<0.3)$ and decreases slightly at large eccentricity ratio $(\varepsilon>0.7)$.

3.5. Flow Rate. The eccentricity ratio as a function of the flow rate is shown in Figure 7. It can be found that the flow rate has almost the same value as that of the eccentricity ratio. There is a reduction in the flow rate as the width ratio is smaller since the hydrostatic effects decrease and the flow rate of deep recessed bearing is almost twice as large as

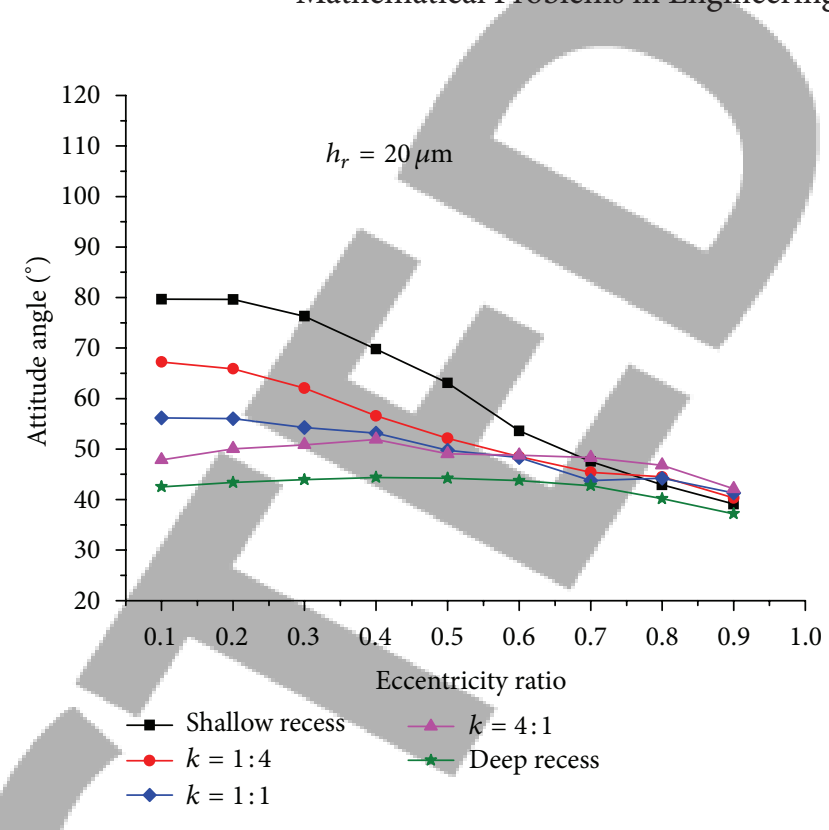

(a)

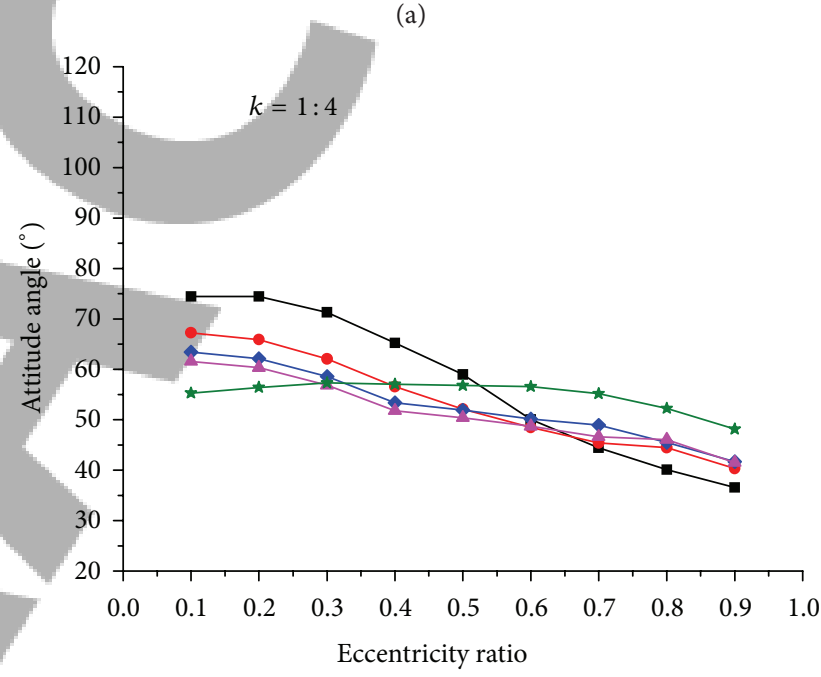

$$
\begin{array}{ll}
\rightarrow h_{r}=10 \mu \mathrm{m} & \rightarrow h_{r}=40 \mu \mathrm{m} \\
\rightarrow-h_{r}=20 \mu \mathrm{m} & \rightarrow h_{r}=50 \mu \mathrm{m}
\end{array}
$$

(b)

FIgURE 6: Attitude angle versus eccentricity ratio. the shallow recessed bearing. Moreover, with the increase of eccentricity ratio, the flow rate of deep/shallow recessed and shallow recessed bearing has a tiny increase, while the flow rate of deep recessed bearing decreases slowly. Furthermore, as the depth of shallow recess is deeper, the turbulent effects increase at the shallow recess region and the flow rate also increases which is seen in Figure 7(b).

3.6. Drag Torque. The drag torque of high-speed deep/shallow recessed hybrid bearing as a function of the eccentricity ratio is presented in Figure 8. The drag torque has almost the same value as the eccentricity ratio is lower and slightly increases as the eccentricity ratio is larger $(\varepsilon>0.7)$. Similarly, The drag torque is larger (twice as big as the deep recessed 


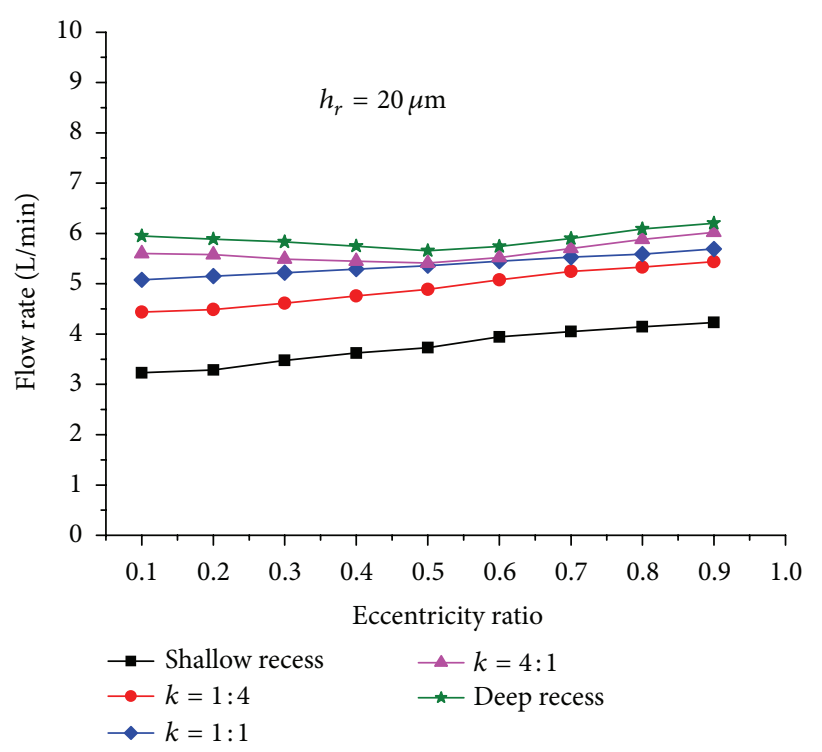

(a)

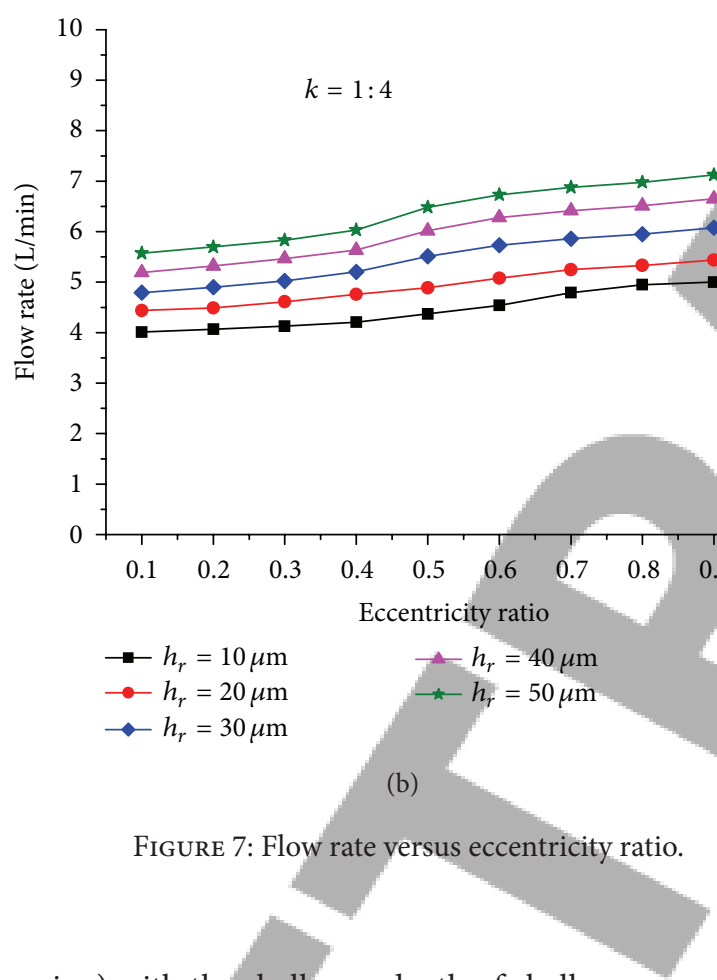

bearing) with the shallower depth of shallow recess and the smaller width ratio due to the increase of wall shear stress. Furthermore, the drag torque of deep recessed bearing is the smallest $(2 \mathrm{~N} / \mathrm{m})$ owing to the larger deep recess; contrarily the drag torque is the largest $(4 \mathrm{~N} / \mathrm{m})$ for the shallow recessed bearing.

\section{Conclusion}

An analysis is conducted and solutions are provided for the effects of the depth and width of shallow recess on the performance of the high-speed deep/shallow recessed hybrid bearing. By adopting bulk flow theory, the turbulent Reynolds equation and energy equation are modified and

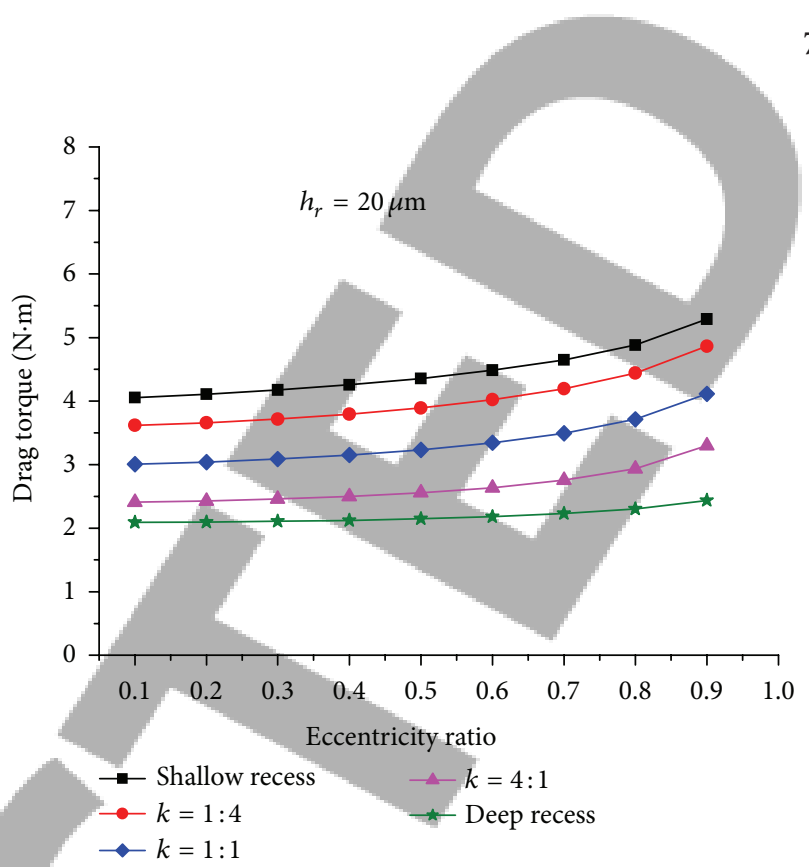

(a)

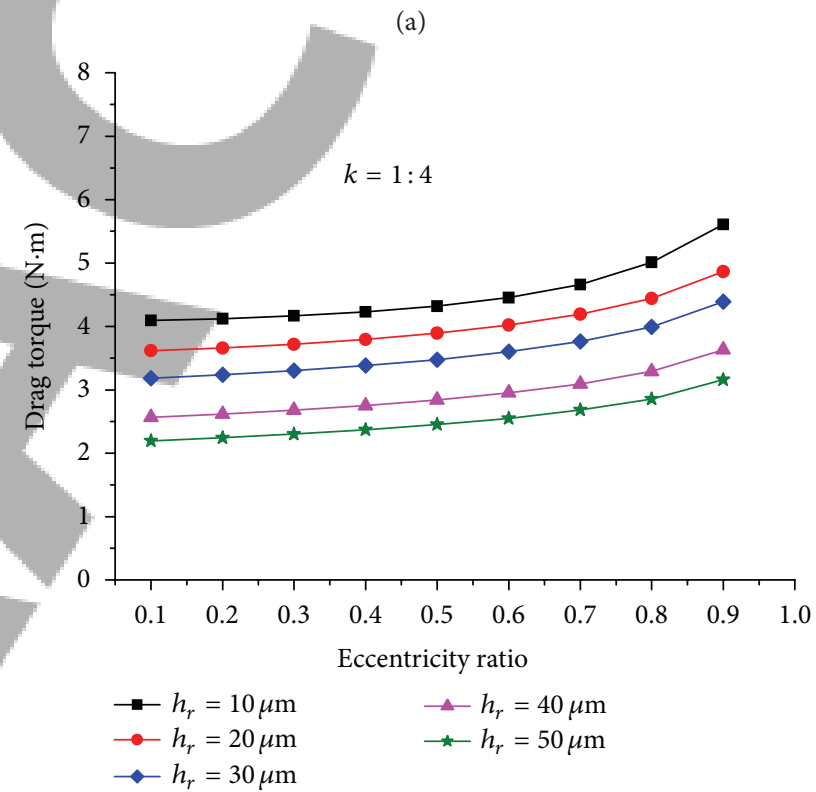

(b)

FIgURE 8: Drag torque versus eccentricity ratio.

solved numerically including concentrated inertia effects at the deep recess edge with different eccentricity ratios. The following conclusions can be obtained.

(1) The depth and width of shallow recess significantly affect the pressure and temperature distribution of the high-speed deep/shallow recessed hybrid bearing. The pressure and temperature rise of the deep/shallow recessed hybrid bearing increases with the shallower recess depth and the smaller width ratio.

(2) The load capacity of the high-speed deep/shallow recessed hybrid bearing significantly increases as well as the flow rate reduces and the drag torque increases with the shallower recess depth and the smaller width 
ratio especially at large eccentricity ratio. In contrast, the flow rate decreases as the depth of shallow recess is shallower and the width ratio is smaller.

(3) In summary, from the view for the high-speed deep/shallow recessed hybrid bearing design, when the eccentricity ratio is large $(\varepsilon>0.4)$, the depth of shallow recess should be designed shallower $\left(h_{r}<\right.$ $30 \mu \mathrm{m})$ and the width ratio should also be designed smaller $(k<1: 1)$ for the high-speed deep/shallow recessed hybrid bearing; otherwise, the deeper shallow recess and the larger width ratio are required in order to reduce the friction power consumption and simplify the design and manufacturing.

\section{Nomenclature}

$h$ : $\quad$ Film thickness

$\bar{H}$ : $\quad$ Nondimensional film thickness

$\theta: \quad$ Angular coordinate

$\omega: \quad$ Journal rotating speed

$\rho: \quad$ Density of lubricant

$p_{e}: \quad \quad$ Pressure at deep recess edge

$G_{x}, G_{z}: \quad$ Turbulent coefficients of circumferential and axial turbulent coefficients

$k_{J}, k_{B}$ : Turbulent shear parameters at shaft and bearing

$V_{x}, V_{z}$ : Bulk flow circumferential and axial velocities

$\tau_{x y}, \tau_{z y}: \quad$ Wall shear stresses

$\left.\tau_{x y}\right|_{0}: \quad$ Turbulent wall shear stress at shaft surface

$T_{R}: \quad$ Drag torque

$A_{0}$ : $\quad$ Orifice sectional area

$d_{c}$ : $\quad$ Diameter of orifice

$A_{r}: \quad$ Recess area

$C_{d}$ :

$Q_{\text {in }}, Q_{\text {out }}$ :

Empirical orifice discharge coefficients

The flow through the orifice restrictor and the deep recess outflow into the film land

$Q_{\text {outc }}, Q_{\text {outa }}$ : Circumferential and radial mass flow

$E_{\text {in }}, E_{\text {out }}: \quad$ The energy flowing into the deep recess and leaving the boundary of the deep recess

$T_{s}$ : $\quad$ Water inlet temperature

$T_{r}: \quad$ Temperature within deep recess and downstream edge

$T_{\text {left }}$ : Temperature in upstream edge

$\xi: \quad$ Empirical recess-edge entrance loss coefficients.

\section{Subscripts}

$s$ : Supply condition

$r$ : Bearing recesses

$B, J$ : Bearing and shaft.

\section{Acknowledgments}

The authors gratefully acknowledge the support of the National Science Foundation through Grant nos. 50775036, 11172065 and Jiangsu University-Industry Collaboration Project through Grant no. BY2012199.

\section{References}

[1] E. Abele, Y. Altintas, and C. Brecher, "Machine tool spindle units," CIRP Annals, vol. 59, no. 2, pp. 781-802, 2010.

[2] W. Xiong, X. Yang, L. Lv, and J. Yuan, "Review on key technology of hydrodynamic and hydrostatic high-frequency motor spindles," Journal of Mechanical Engineering, vol. 45, no. 9, pp. 1-18, 2009.

[3] W. B. Rowe, "A theoretical and experimental investigation of self compensated externally pressurized thrust bearings," in Proceedings of the 6th Symposium on Gas Bearing, 1974.

[4] G. Hong, L. Xinmin, W. Xiaoling, and C. Shaoqi, "Performance of flat capillary compensated deep/shallow pockets hydrostatic/hydrodynamic journal-thrust floating ring bearing," Tribology Transactions, vol. 52, no. 2, pp. 204-212, 2009.

[5] H. Guo, S. Lin Zhang, and S. Qi Cen, "Theoretical and experimental study on dynamic coefficients and stability for a hydrostatic/hydrodynamic conical bearing," Journal of Tribology, vol. 131, pp. 701-708, 2009.

[6] D. Pan, Z. Yabin, and X. Hua, "The structure of new journal hybrid bearing for high-speed machine spindle and its performance," Lubrication Engineering, vol. 34, no. 2, pp. 11-14, 2009.

[7] C.-H. Chen, Y. Kang, Y.-N. Huang, C.-H. Chu, and J.-T. Teng, "The restrictive effects of capillary compensation on the stability of the Jeffcott rotor-hybrid bearing system," Tribology International, vol. 35, no. 12, pp. 849-855, 2002.

[8] W. Chen, F. Wang, and Y. Zhang, "The flow field simulation of a novel water-lubricated hybrid bearing for high-speed spindle," in Proceedings of the STLE/ASME International Joint Tribology Conference (IJTC '10), pp. 91-93, October 2010.

[9] N. Heinrichson, I. F. Santos, and A. Fuerst, "The influence of injection pockets on the performance of tilting-pad thrust bearings-part I. Theory," Journal of Tribology, vol. 129, no. 4, pp. 895-903, 2007.

[10] H. Guo, S. Lin Zhang, and S. Qi Cen, "Research on static characteristics of deep/shallow pockets hybrid bearing under laminar and turbulent mixed regimes," in Advanced Materials Research, Materials Processing Technology, vol. 291-294, pp. 1516-1520, 2011.

[11] C.-H. Chen, Y. Kang, Y.-P. Chang, H.-H. Lee, and P.-C. Shen, "Influences of recess depth on the stability of the Jeffcott rotor supported by hybrid bearings with orifice restrictors," Industrial Lubrication and Tribology, vol. 57, no. 1, pp. 41-51, 2005.

[12] C. H. Chen, Y. Kang, Y.-P. Chang, Y.-P. Wang, and H.-H. Lee, "Influence of restrictor on stability of the rigid rotor-hybrid bearing system," Journal of Sound and Vibration, vol. 297, no. 3-5, pp. 635-648, 2006.

[13] M. Helene, M. Arghir, and J. Frene, "Numerical study of the pressure pattern in a two-dimensional hybrid journal bearing recess, laminar, and turbulent flow results," Journal of Tribology, vol. 125, no. 2, pp. 283-290, 2003.

[14] G. G. Hirs, "A bulk-flow theory for turbulence in lubricant films," Journal of Lubrication Technology, vol. 95, no. 2, pp. 137146, 1973.

[15] B. J. Hamrock, S. R. Schmid, and B. O. Jacobson, Fundamentals of Fluid Film Lubrication, 2004.

[16] V. N. Constantinescu and S. Galetuse, "Pressure drop due to inertia forces in step bearings," Journal of Lubrication Technology, vol. 98, no. 1, pp. 167-174, 1976.

[17] J. Frêne, M. Arghir, and V. Constantinescu, "Combined thinfilm and Navier-Stokes analysis in high Reynolds number 
Mathematical Problems in Engineering

lubrication," Tribology International, vol. 39, no. 8, pp. 734-747, 2006.

[18] A. Z. Szeri, Fluid Film Lubrication: Theory and Design, Cambridge University Press, 1998.

[19] S. M. Chun and D.-H. Ha, "Study on mixing flow effects in a high-speed journal bearing," Tribology International, vol. 34, no. 6, pp. 397-405, 2001.
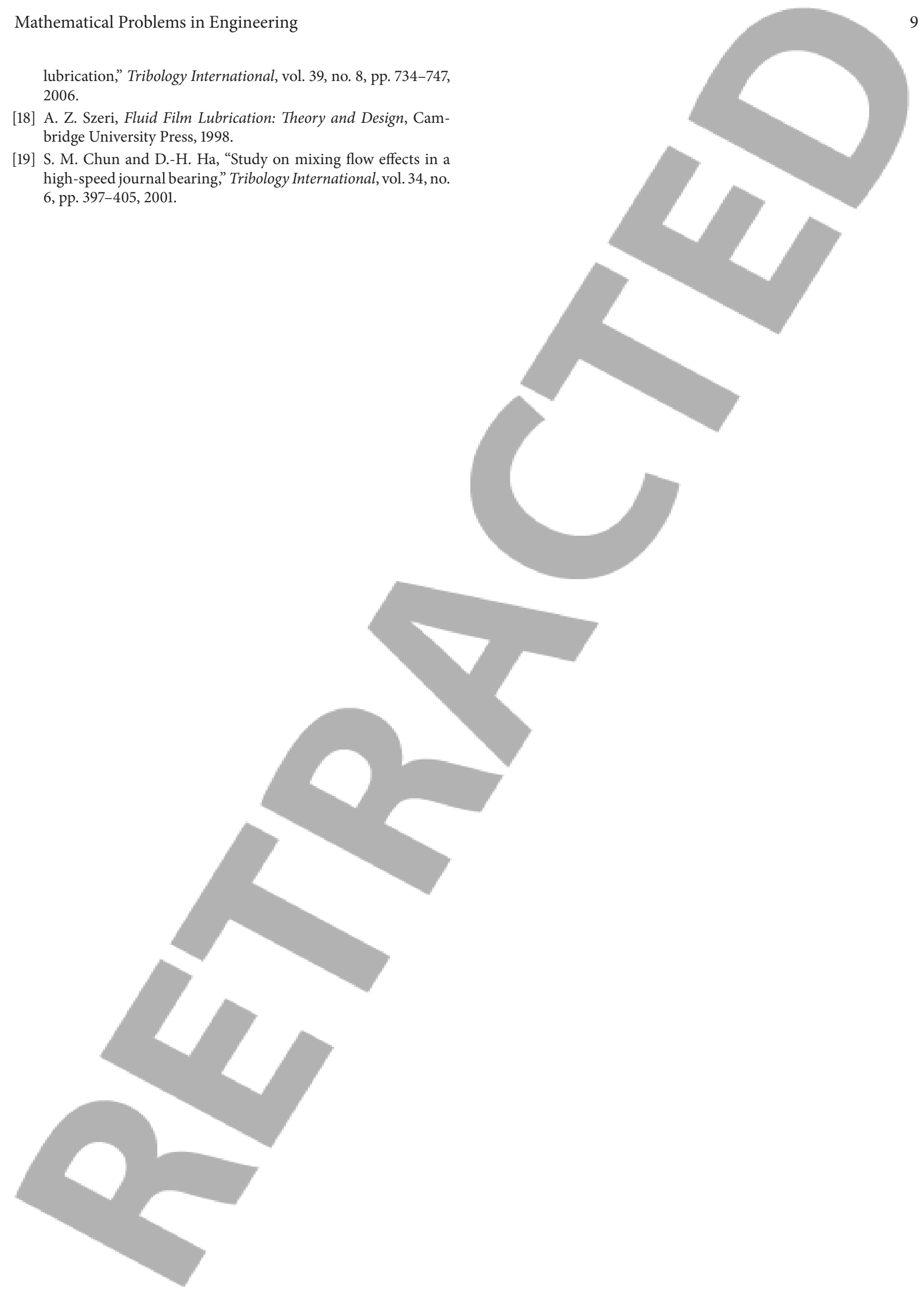